\title{
Nanoencapsulation I. Methods for preparation of drug-loaded polymeric nanoparticles
}

\author{
Catarina Pinto Reis, PhD, ${ }^{a}$ Ronald J. Neufeld, $\mathrm{PhD},{ }^{\mathrm{b}, *}$ \\ António J. Ribeiro, $\mathrm{PhD},{ }^{\mathrm{c}}$ Francisco Veiga, $\mathrm{PhD}^{\mathrm{a}}$ \\ ${ }^{a}$ Laboratório Tecnologia Farmacêutica, Faculdade de Farmácia, Universidade de Coimbra, Coimbra, Portugal \\ ${ }^{\mathrm{b}}$ Chemical Engineering Department, Queen's University, Kingston, Ontario, Canada \\ ${ }^{\mathrm{c}}$ Departamento Tecnologia Farmacêutica, I.S.C.S.N., Gandra, Paredes, Portugal \\ Received 21 August 2005; Accepted 20 December 2005
}

\begin{abstract}
Polymeric nanoparticles have been extensively studied as particulate carriers in the pharmaceutical and medical fields, because they show promise as drug delivery systems as a result of their controlled- and sustained-release properties, subcellular size, and biocompatibility with tissue and cells. Several methods to prepare nanoparticles have been developed during the last two decades, classified according to whether the particle formation involves a polymerization reaction or arises from a macromolecule or preformed polymer. In this review the most important preparation methods are described, especially those that make use of natural polymers. Advantages and disadvantages will be presented so as to facilitate selection of an appropriate nanoencapsulation method according to a particular application.
\end{abstract}

(C) 2006 Elsevier Inc. All rights reserved.

Nanoencapsulation of drugs involves forming drugloaded particles with diameters ranging from 1 to $1000 \mathrm{~nm}$. Nanoparticles are defined as solid, submicron-sized drug carriers that may or may not be biodegradable $[1,2]$. The term nanoparticle is a collective name for both nanospheres and nanocapsules. Nanospheres have a matrix type of structure. Drugs may be absorbed at the sphere surface or encapsulated within the particle. Nanocapsules are vesicular systems in which the drug is confined to a cavity consisting of an inner liquid core surrounded by a polymeric membrane [1]. In this case the active substances are usually dissolved in the inner core but may also be adsorbed to the capsule surface [3]. Nanoparticles are receiving considerable attention for the delivery of therapeutic drugs. The literature emphasizes the advantages of nanoparticles over microparticles [4] and liposomes $[5,6]$. The submicron size of nanoparticles offers

* Corresponding author. Chemical Engineering Department, Dupuis Hall, Queens University, Kingston, Ontario, Canada K7L3N6.

E-mail address: neufeld@chee.queensu.ca (R.J. Neufeld). a number of distinct advantages over microparticles, including relatively higher intracellular uptake compared with microparticles. In terms of intestinal uptake, apart from their particle size, nanoparticle nature and charge properties seem to influence the uptake by intestinal epithelia. Uptake of nanoparticles prepared from hydrophobic polymers seems to be higher than that of particles with more hydrophilic surfaces [7], thus more hydrophilic particles may be rapidly eliminated. Generally, nanoparticles based in hydrophobic polymers such as poly(styrene), uncharged and positively charged, provide an affinity to follicle-associated epithelia as well as to absorptive enterocytes, whereas negatively charged poly (styrene) nanoparticles show only low affinity to any type of intestinal tissues. In contrast, nanoparticles based on hydrophilic polymers, negatively charged, show a strong increase in bioadhesive properties and are absorbed by both $\mathrm{M}$ cells and absorptive enterocytes. A combination of both nanoparticle surface charges and increased hydrophilicity of the matrix material seem to affect the gastrointestinal uptake in a positive sense. 
The nanoparticle surface is also a very important consideration in targeting drug delivery. Indeed, once in the bloodstream, generally conventional nanoparticles (no surface modification) and negatively charged particles can be rapidly opsonized and massively cleared by the fixed macrophages. It is well known that the reticuloendothelial system, mainly the liver and spleen, is a major obstacle to active targeting because of its ability to recognize these systems, remove them from systemic circulation, and, consequently, avoid the effective delivery of the nanospheres to organs other than those of the reticuloendothelial system [8]. Surface modification of these nanoparticulate systems with hydrophilic polymers is the most common way to control the opsonization process and to improve the surface properties of the system, or coating modification with polymers [6] such as the attachment of poly(ethylene glycol) (PEG) chains to biodegradable polymer such as poly(lactic acid) (PLA) and poly(lactic-co-glycolic acid) (PLGA). Thus the hydrophilic PEG chains allow the control of protein and peptide absorption and, in addition will allow regulation of cell behavior at the polymer surface.

Thus the polymeric composition (hydrophobicity, surface charge, and biodegradation profile) of the nanoparticles, any adjuvant substances, and the associated drug (molecular weight, charge, localization in the nanospheres by adsorption or incorporation) have a great influence on the drug absorption, biodistribution pattern, and elimination. There are now numerous preparation methods available for producing nanoparticles.

Depending on the physicochemical characteristics of a drug, it is now possible to choose the best method of preparation and the best polymer to achieve an efficient entrapment of the drug. Moreover, organic solvents assessed in this review are classified according to International Conference on Harmonization (ICH) classification according to their possible risk to human health and placed into one of three classes as follows: class 1 (solvents to be avoided), class 2 (solvents to be limited), and class 3 (solvents with low toxic potential). This classification will be crucial to evaluate the following methods and finally, to apply a specific technique to a particular pharmaceutical application.

\section{Methods}

Many methods have been developed for preparing nanoparticles; these methods can be classified into two main categories according to whether the formulation requires a polymerization reaction or is achieved directly from a macromolecule or preformed polymer [1]. The polymerization methods can be further classified into emulsion and interfacial polymerization, and there are two types of emulsion polymerization - organic and aqueous-depending on the continuous phase. Additionally, the interfacial condensation method will be further discussed later in this review. Nanoparticles can be also prepared directly from preformed synthetic or natural polymers and by desolvation of macromolecules. Recently these polymeric systems have been prepared by nebulization techniques. This review covers all these methods including their detailed procedures and technological advantages, as well as providing several examples of encapsulants that are entrapped into or adsorbed to these particles. The most important methods of nanoparticle preparation, as well as the encapsulants and the resulting approximate particle sizes, are shown in Table 1.

\section{Nanoparticles obtained by polymerization of a monomer}

\section{Emulsion polymerization}

Emulsion polymerization is one of the fastest methods for nanoparticle preparation and is readily scalable [9]. The method is classified into two categories, based on the use of an organic or aqueous continuous phase.

The continuous organic phase methodology involves the dispersion of monomer into an emulsion or inverse microemulsion, or into a material in which the monomer is not soluble (nonsolvent). Polyacrylamide nanospheres were produced by this method [10,11]. As one of the first methods for production of nanoparticles, surfactants or protective soluble polymers were used to prevent aggregation in the early stages of polymerization [12]. This procedure has become less important, because it requires toxic organic solvents, surfactants, monomers and initiator, which are subsequently eliminated from the formed particles. As a result of the nonbiodegradable nature of this polymer as well as the difficult procedure, alternative approaches are of greater interest. Later, poly(methylmethacrylate) (PMMA), poly(ethylcyanoacrylate) (PECA), and poly(butylcyanoacrylate) [13] nanoparticles were produced by dispersion via surfactants into solvents such as cyclohexane (ICH, class 2), n-pentane (ICH, class 3), and toluene ( $\mathrm{ICH}$, class 2) as the organic phase. Examples of drugs encapsulated with this system are triamcinolone [14], fluorescein [13], pilocarpine [15], and timolol [15].

In the aqueous continuous phase the monomer is dissolved in a continuous phase that is usually an aqueous solution, and the surfactants or emulsifiers are not needed. The polymerization process can be initiated by different mechanisms. Initiation occurs when a monomer molecule dissolved in the continuous phase collides with an initiator molecule that might be an ion or a free radical. Alternatively, the monomer molecule can be transformed into an initiating radical by high-energy radiation, including $\gamma$-radiation, or ultraviolet or strong visible light. Chain growth starts when initiated monomer ions or monomer radicals collide with other monomer molecules according to an anionic polymerization mechanism [16]. Phase separation and formation of solid particles can take place before or after termination of the polymerization reaction [17].

PMMA nanoparticles are suitable adjuvants for vaccines and are produced by a radical emulsion polymerization mechanism [18] — generally without emulsifiers [19]. The single monomer methylmethacrylate (MMA) was used to 
Table 1

Examples of preparative methods, polymers, and encapsulants

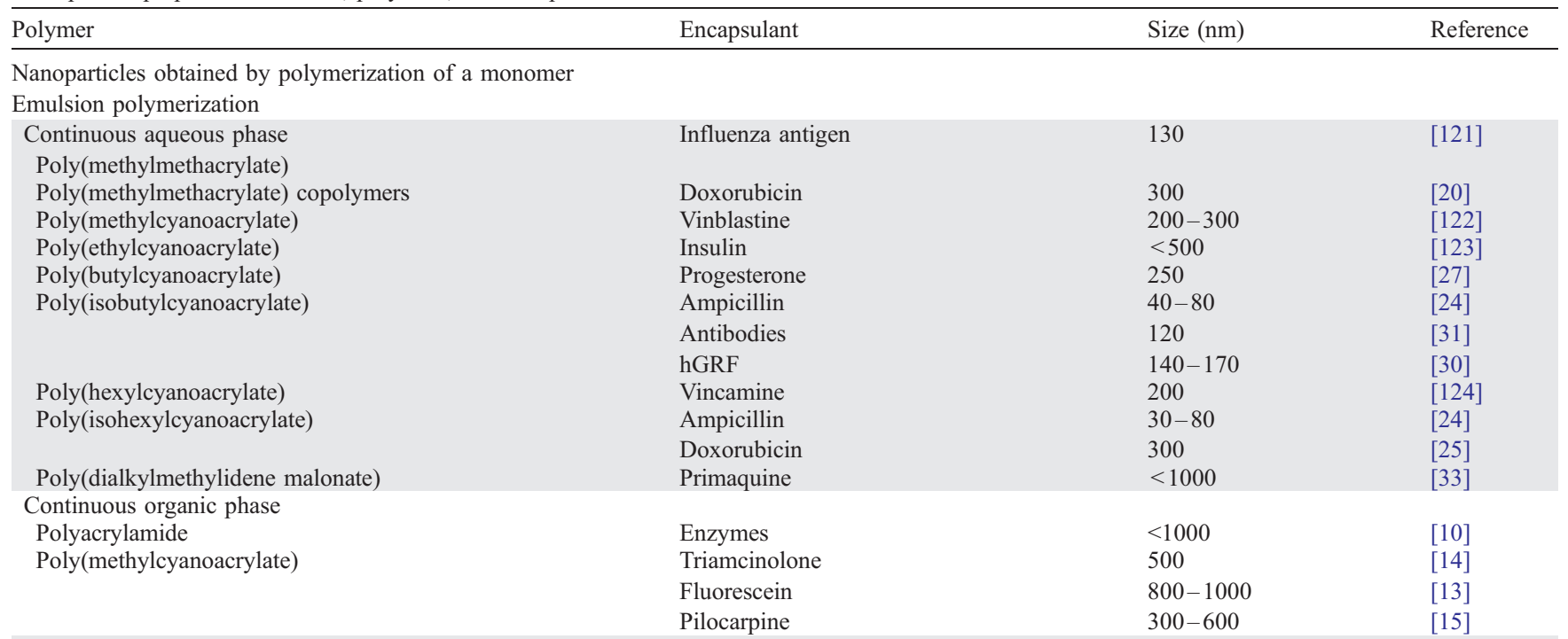

Other polymers: Poly(ethylcyanoacrylate), poly(butylcyanoacrylate), poly(styrene), poly(vinylpyridine) and poly(acroleine)

Interfacial polymerization

Poly(ethylcyanoacrylate)

Poly(isobutylcyanoacrylate)

Insulin
Indomethacin
Darodipine
Insulin
Calcitonin
Octreotide
Phthalocyanines

Poly(isohexylcyanoacrylate)

Other polymers: Polyamides, poly(phenylesters) and polyurethanes

Interfacial polycondensation

Polyurethane and poly(etherurethane)

Nanoparticles obtained directly from a macromolecule

or a preformed polymer

Nanoparticles prepared with synthetic/semi-synthetic

preformed polymer

Solvent evaporation

Poly(lactic acid)

Poly(lactic acid)-poly(glycolic acid) copolymer

Other polymers: Poly( $\varepsilon$-caprolactone) and poly( $\beta$-Hydroxybutyrate)

Solvent displacement

Poly(lactic acid)-poly(glycolic acid) copolymer

Poly( $\varepsilon$-caprolactone)

$\alpha$-Tocopherol

$<500$

$\sim 151$

220240

150

$150-300$

$<1000$

260

180

$\begin{array}{lll}\text { Testosterone } & <1000 & {[52]} \\ \text { Albumin } & 100 \text { or } 120 & {[61]} \\ \text { Tetanus toxoid } & 150 & {[62]} \\ \text { Loperamide } & \sim 300 & {[53,63]} \\ \text { DNA } & \sim 100 & {[67]} \\ \text { Cyclosporin A } & \sim 300 & {[66]}\end{array}$

Cyclosporin A

60

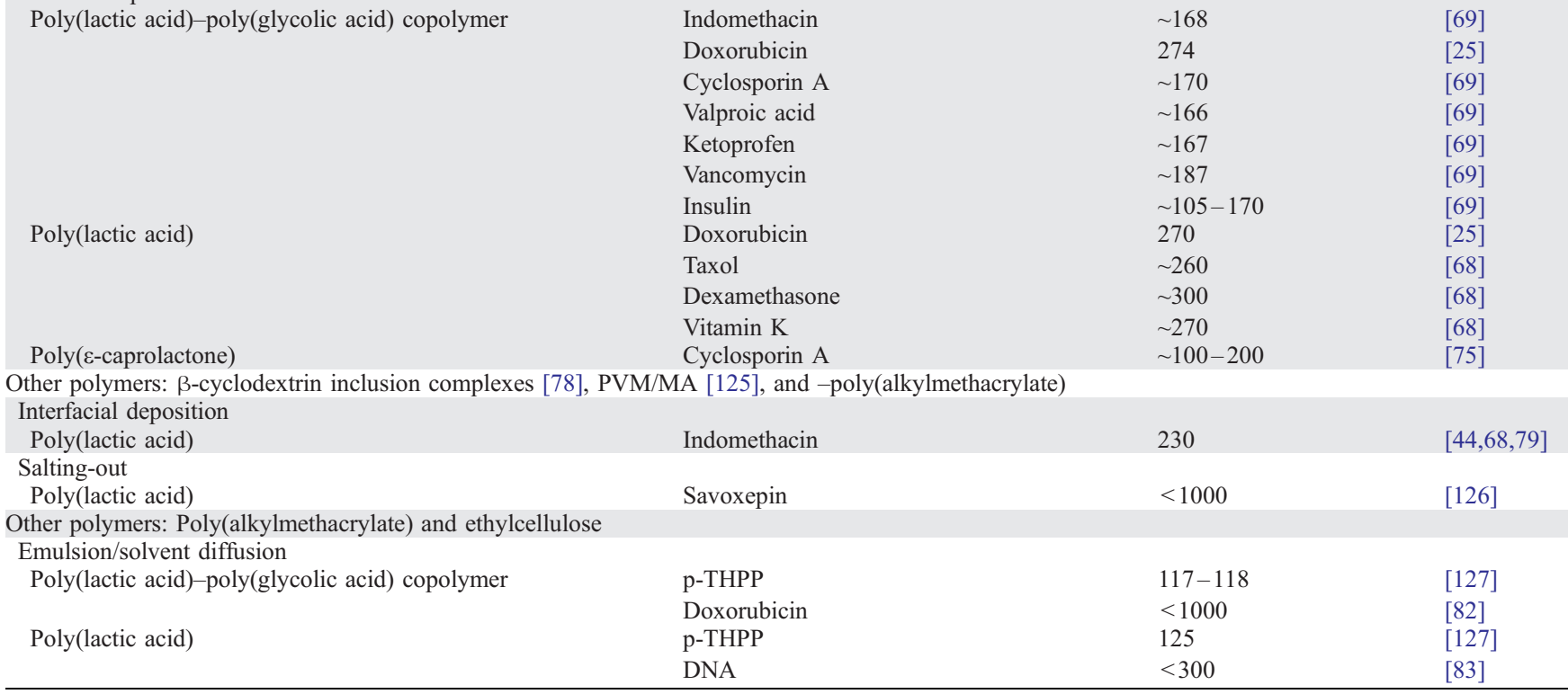


Table 1 (continued)

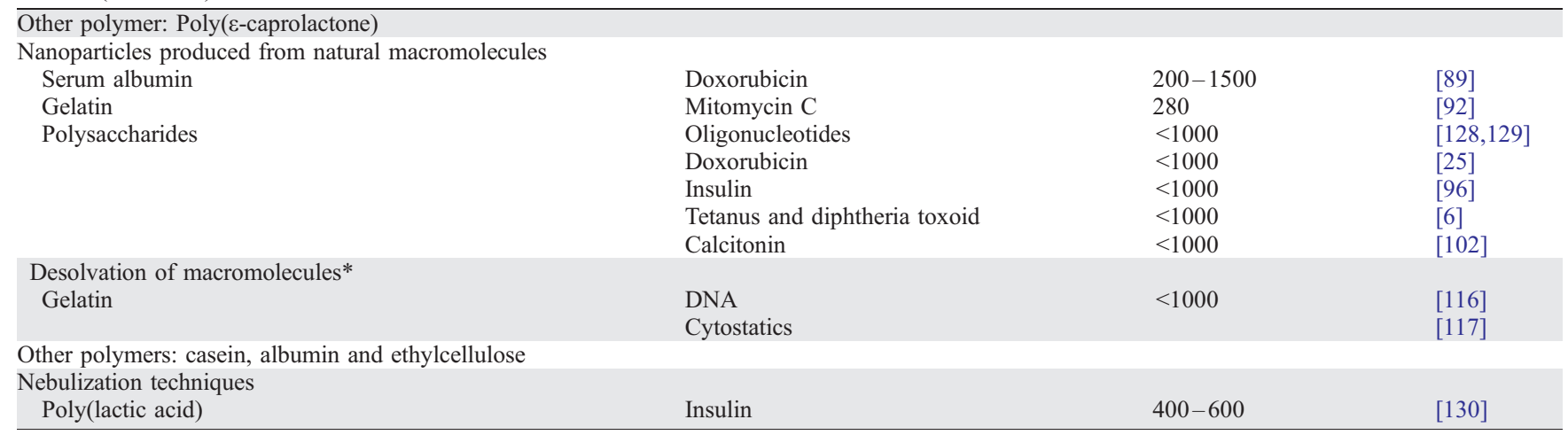

hGRF, human growth hormone-releasing factor; p-THPP, mesotetra(hydroxyphenyl)porphyrin.

* Induced by heat, $\mathrm{pH}$ changes, salts, organic solvents, complexing with macromolecules, sonication, or chemical cross-linking.

produce PMMA nanospheres until 1986, when the copolymerization of MMA, hydroxypropylmethacrylate, methacrylic acid, and ethylene glycol dimethacrylate was described to increase the hydrophilicity of the particles with the intention of modifying the distribution of the particles within the body [3]. Various drugs or tracers were encapsulated into nanospheres with high entrapment efficiencies (eg, doxorubicin) [20]. The preparation of PMMA nanospheres is simple and drugs can be successfully entrapped, but two drawbacks have to be kept in mind. First, polymerization requires a chemical or physical initiation, and second, PMMA nanospheres are not biodegradable [21].

As a result, poly(alkylcyanoacrylate) (PACA) nanoparticles seem to be a good alternative, in that PACA is readily biodegradable [22]. Polymerization occurs at room temperature and requires neither $\gamma$-irradiation nor a chemical initiator [23], thus avoiding heat and highenergy radiation. The polymerization mechanism is an anionic process. Hydrophilic drugs are encapsulated with good efficiency, such as that for ampicillin [24] and doxorubicin [25]. The percentage of drug incorporated or adsorbed decreases generally with the increasing amount of drug in the polymerization medium [26]. Sparingly water-soluble molecules such as progesterone [27], triamcinolone diacetate [28], can also be loaded in PACA nanospheres but must be dissolved in a solvent such as ether ( $\mathrm{ICH}$, class 3 ) or in a liquid surfactant before being added to the aqueous polymerization medium. Insulin [29], growth hormone-releasing factors (GRFs) [30], and monoclonal antibodies [31] can also be incorporated into PACA nanospheres.

As well, poly(dialkylmethylidene malonate) nanospheres were prepared at $\mathrm{pH} 6$ [32]. The main difference is that the cyano group is replaced by an alkyloxycarbonyl group that is less reactive in the presence of the hydroxide ion initiator. Poly(diethylmethylidene malonate) nanospheres loaded with primaquine have also been prepared at $\mathrm{pH} 7.4$ [33]. The entrapment efficiency rose to $100 \%$ when the drug was added to the polymerization medium.

\section{Interfacial polymerization}

\section{Poly(alkylcyanoacrylate) nanoparticles}

One of the advantages of these polymers is their very rapid polymerization-occurring during seconds-initiated by ions present in the medium [34]. Cyanoacrylate monomer and drug were dissolved in a mixture of an oil and absolute ethanol [35]. This mixture was then slowly extruded through a needle into a well-stirred aqueous solution, with or without some ethanol ( $\mathrm{ICH}$, class 3 ) or acetone (ICH, class 3) containing surfactant. Nanocapsules are formed spontaneously by polymerization of cyanoacrylate after contact with initiating ions present in the water. The resulting colloidal suspension can be concentrated by evaporation under vacuum. PECA [36], poly(isobutylcyanoacrylate) $[37,38]$, and poly(isohexylcyanoacrylate) [39] were used in production of nanoparticles by this process. Examples of drugs encapsulated are insulin [36,40], calcitonin [11], octreotide [41], darodipine [42], indomethacin $[43,44]$, and photoactivatable cytotoxic compounds used in photodynamic tumor therapy like phthalocyanines in an injectable vehicle [39]. To encapsulate highly watersoluble drugs, another method has been proposed $[45,46]$. Besides the monomer, potentially toxic compounds were not used, thus no purification procedure was necessary. The final product was a suspension of nanocapsules in Migliol, which is an acceptable excipient for oral administration. Encapsulation efficiencies reached $50 \%$ and $30 \%$ for the larger and the smaller capsules, respectively [47].

An advantage of interfacial polymerization techniques is high-efficiency drug encapsulation (eg, insulin with 95\%) [34]. In addition, the advantage of obtaining nanocapsules by this method is that the polymer is formed in situ, allowing the polymer membrane to follow the contours of the inner phase of an oil/water or water/oil emulsion [34]. In this case, the main disadvantage is the use of organic solvents required for the external phase. Washing of solvents and replacement by water represents a timeconsuming and difficult procedure [3]. 


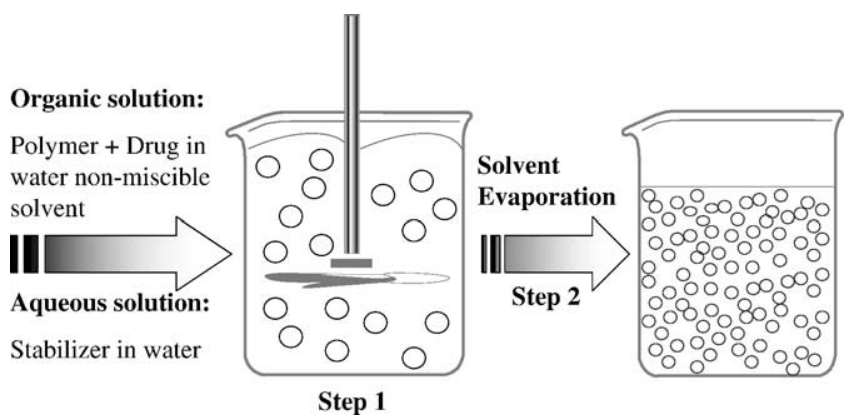

Fig 1. Schematic representation of the emulsification-evaporation technique.

\section{Interfacial polycondensation}

Polymeric nanoparticles can be also prepared by the interfacial polycondensation of the lipophilic monomer, such as phtaloyldichloride and the hydrophilic monomer, diethylenetriamine, in the presence and absence of the surfactant [48]. These nanoparticles were smaller than $500 \mathrm{~nm}$. A modified interfacial polycondensation method was also developed. In this case, polyurethane polymer and poly (ether urethane) copolymers were chosen and successfully applied as drug carriers for $\alpha$-tocopherol [49]. Polyurethaneand poly(ether urethane)-based nanocapsules were synthesized by interfacial reaction between two monomers.

\section{Nanoparticles obtained from preformed polymers}

With the exception of alkylcyanoacrylates and poly (dialkylmethylidene malonate), most of the monomers suitable for a micellar polymerization process in an aqueous phase lead to slowly biodegradable or nonbiodegradable polymers. In addition, residual molecules in the polymerization medium (monomer, oligomer, surfactant, etc.) can be more or less toxic, requiring meticulous purification of the colloidal material. To avoid these limitations, methods using preformed polymers instead of monomers have been proposed.

\section{Synthetic preformed polymers}

\section{Emulsification/solvent evaporation}

Emulsification-solvent evaporation involves two steps. The first step requires emulsification of the polymer solution into an aqueous phase (see Figure 1). During the second step polymer solvent is evaporated, inducing polymer precipitation as nanospheres.

A polymer organic solution containing the dissolved drug is dispersed into nanodroplets, using a dispersing agent and high-energy homogenization [50], in a nonsolvent or suspension medium such as chloroform (ICH, class 2) or ethyl acetate (ICH, class 3 ). The polymer precipitates in the form of nanospheres in which the drug is finely dispersed in the polymer matrix network. The solvent is subsequently evaporated by increasing the temperature under pressure or by continuous stirring [6]. The size can be controlled by adjusting the stir rate, type and amount of dispersing agent, viscosity of organic and aqueous phases, and temperature [50]. Even though different types of emulsions may be used, oil/water emulsions are of interest because they use water as the nonsolvent; this simplifies and thus improves process economics, because it eliminates the need for recycling, facilitating the washing step and minimizing agglomeration [51]. However, this method can only be applied to liposoluble drugs, and limitations are imposed by the scale-up of the high energy requirements in homogenization [6]. Frequently used polymers are PLA [52,53], PLGA [54], ethylcellulose (EC) [55], cellulose acetate phthalate [3], poly( $\varepsilon$-caprolactone) (PCL) [56-58], and poly( $\beta$-hydroxybutyrate) (PHB) $[59,60]$. Drugs or model drugs encapsulated were albumin [61], texanus toxoid [62], testosterone [52], loperamide [53,63], prazinquantel [64], cyclosporin A [65,66], nucleic acid [67], and indomethacin [55].

\section{Solvent displacement and interfacial deposition}

Solvent displacement and interfacial deposition are similar methods based on spontaneous emulsification of the organic internal phase containing the dissolved polymer into the aqueous external phase (see Figure 2). However, solvent displacement forms nanospheres or nanocapsules, whereas interfacial deposition forms only nanocapsules.

Solvent displacement involves the precipitation of a preformed polymer from an organic solution and the diffusion of the organic solvent in the aqueous medium in the presence or absence of a surfactant [68-71]. The polymer, generally PLA, is dissolved in a water-miscible solvent of intermediate polarity, leading to the precipitation of nanospheres. This phase is injected into a stirred aqueous solution containing a stabilizer as a surfactant. Polymer deposition on the interface between the water and the organic solvent, caused by fast diffusion of the solvent, leads to the instantaneous formation of a colloidal suspension [72]. To facilitate the formation of colloidal polymer particles during the first step of the procedure, phase separation is performed with a totally miscible solvent that is also a nonsolvent of the

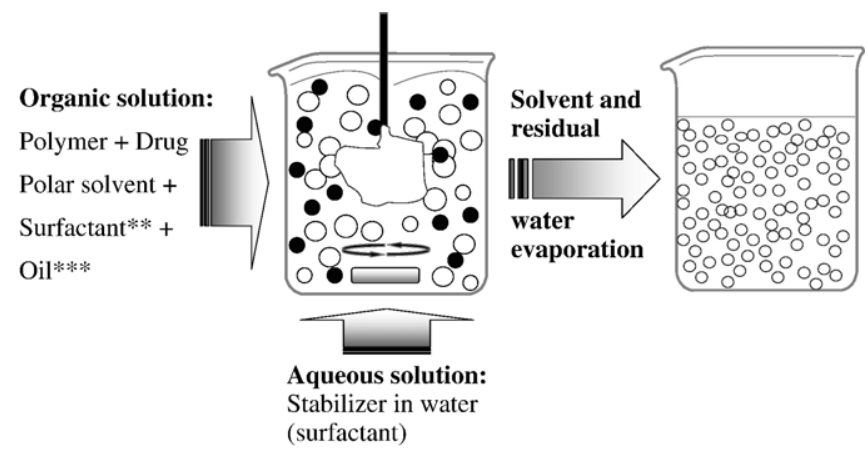

Fig 2. Schematic representation of the solvent displacement technique. **Surfactant is optional. ***In interfacial deposition method, a fifth compound was introduced only on preparation of nanocapsules. 


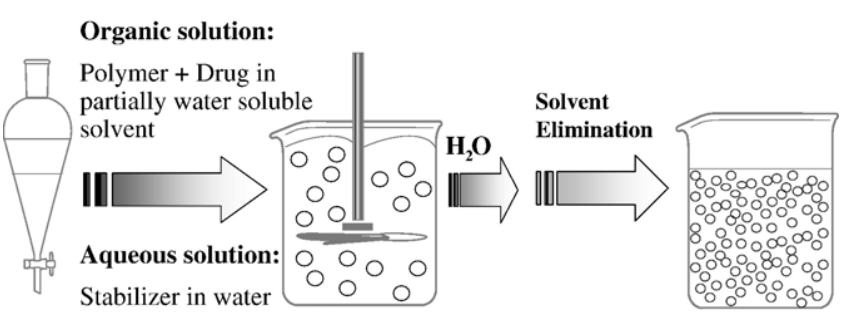

Fig 3. Schematic illustration of the ESD technique.

polymer [16]. The solvent displacement technique allows the preparation of nanocapsules when a small volume of nontoxic oil is incorporated in the organic phase [72]. Considering the oil-based central cavities of the nanocapsules, high loading efficiencies are generally reported for lipophilic drugs when nanocapsules are prepared [72]. The usefulness of this simple technique [72] is limited to water-miscible solvents, in which the diffusion rate is enough to produce spontaneous emulsification. Then, even though some water-miscible solvents produce a certain instability when mixed in water, spontaneous emulsification is not observed if the coalescence rate of the formed droplets is sufficiently high [73]. Although, acetone/dichloromethane ( $\mathrm{ICH}$, class 2) are used to dissolve and increase the entrapment of drugs, the dichloromethane increases the mean particle size [74] and is considered toxic. This method is basically applicable to lipophilic drugs because of the miscibility of the solvent with the aqueous phase [69], and it is not an efficient means to encapsulate water-soluble drugs.

In fact, it seems difficult to choose a drug/polymer/ solvent/nonsolvent system in which particles would be formed and the drug efficiently entrapped, because the solvent and the nonsolvent of the polymer must be mutually miscible. The progressive addition of the polymer solution to the nonsolvent generally leads to the formation of nanospheres close to $200 \mathrm{~nm}$ in size. Nanoparticles seem to be formed by a mechanism comparable to the "diffusion and standing" process found in spontaneous emulsification. This phenomenon has been explained by local variations of the interfacial tension between the two immiscible liquids due to the mutual diffusion of the third liquid. This method has been applied to various polymeric materials such as PLA [25], PLGA [69], PCL [75], and poly(methyl vinyl ether-comaleic anhydride) (PVM/MA) [76,77]. This technique was well adapted for the incorporation of cyclosporin A, because entrapment efficiencies as high as $98 \%$ were obtained [47]. Highly loaded nanoparticulate systems based on amphiphilic $\beta$-cyclodextrins to facilitate the parenteral administration of the poorly soluble antifungal drugs bifonazole and clotrimazole were prepared according to the solvent displacement method [78].

Interfacial deposition is a process used for the production of nanocapsules; however, this is not a polymerization technique but an emulsification/solidification technique. In interfacial deposition, a fifth compound is introduced, of oil nature, miscible with the solvent of the polymer but immiscible with the mixture. The polymer deposits on the interface between the finely dispersed oil droplets and the aqueous phase, forming nanocapsules [1]. An aqueous solution is used as the dispersing medium. The main difference is that polymers such as PLA are dissolved together with the drug in a solvent mixture (eg, benzyl benzoate, acetone, and phospholipids) [24]. This mixture is injected slowly into a stirred aqueous medium, resulting in the deposition of the polymer in the form of nanoparticles of about $230 \mathrm{~nm}$ in size [44,68,79]. Polymer deposition occurs at the interface between water and benzoyl nanodroplets, forming nanocapsules with a shell-like wall [44].

\section{Emulsification/solvent diffusion}

Emulsification/solvent diffusion (ESD) was proposed in the literature based on the use of organic solvents, and then it was adapted to the following salting-out procedure. The encapsulating polymer is dissolved in a partially watersoluble solvent such as propylene carbonate (ICH not given) and saturated with water to ensure the initial thermodynamic equilibrium of both liquids. In fact, to produce the precipitation of the polymer and the consequent formation of nanoparticles, it is necessary to promote the diffusion of the solvent of the dispersed phase by dilution with an excess of water when the organic solvent is partly miscible with water or with another organic solvent in the opposite case. Subsequently, the polymer-water saturated solvent phase is emulsified in an aqueous solution containing stabilizer, leading to solvent diffusion to the external phase and the formation of nanospheres or nanocapsules, according to the oil-to-polymer ratio. Finally, the solvent is eliminated by evaporation or filtration, according to its boiling point. The procedure is illustrated in Figure 3.

This technique presents several advantages, such as high encapsulation efficiencies (generally $>70 \%$ ), no need for homogenization, high batch-to-batch reproducibility, ease of scale-up, simplicity, and narrow size distribution. Disadvantages are the high volumes of water to be eliminated from the suspension and the leakage of water-soluble drug into the saturated-aqueous external phase during emulsification, reducing encapsulation efficiency. As with some of the other techniques, this one is efficient in encapsulating lipophilic drugs

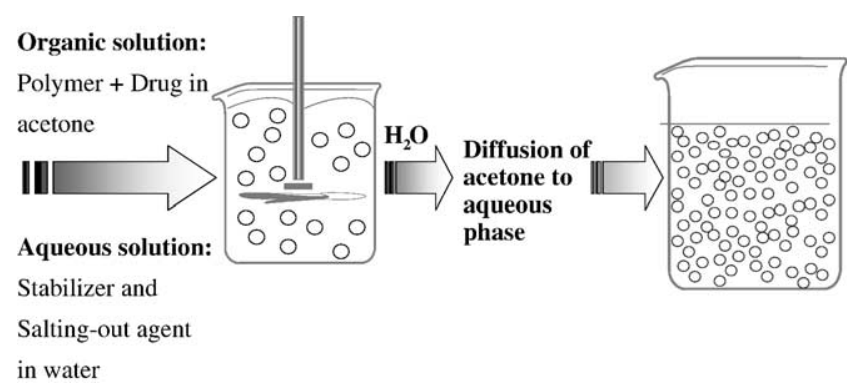

Fig 4. Schematic of the salting-out technique. 


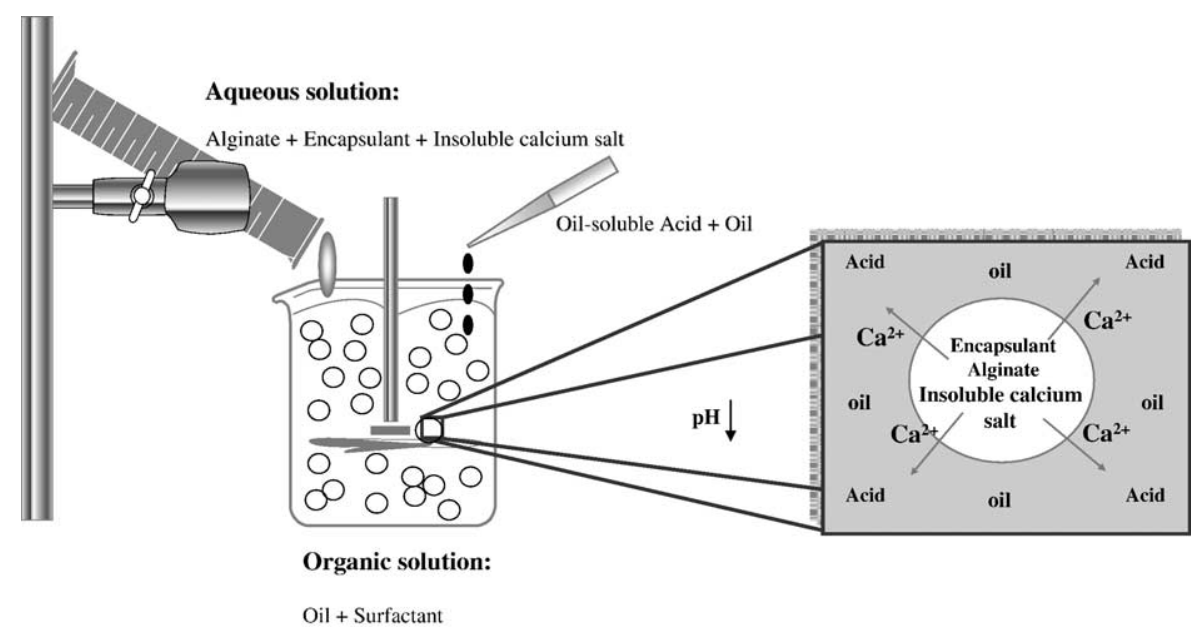

Fig 5. Schematic representation of the emulsification-internal gelation technique using alginate.

[72]. Several drug-loaded nanoparticles were produced by the ESD technique, including mesotetra(hydroxyphenyl) porphyrin-loaded PLGA (p-THPP) nanoparticles [80,81], doxorubicin-loaded PLGA nanoparticles [82], plasmid DNA-loaded PLA nanoparticles [83], coumarin-loaded PLA nanoparticles [84], indocyanine [85], cyclosporin (Cy-A)-loaded gelatin and cyclosporin (Cy-A)-loaded sodium glycolate nanoparticles [86].

\section{Salting out with synthetic polymers}

Salting-out is based on the separation of a watermiscible solvent from aqueous solution via a salting-out effect. The salting-out procedure can be considered as a modification of the emulsification/solvent diffusion. Polymer and drug are initially dissolved in a solvent such as acetone, which is subsequently emulsified into an aqueous gel containing the salting-out agent (electrolytes, such as magnesium chloride, calcium chloride, and magnesium acetate, or non-electrolytes such as sucrose) and a colloidal stabilizer such as polyvinylpyrrolidone or hydroxyethylcellulose. This oil/water emulsion is diluted with a sufficient volume of water or aqueous solution to enhance the diffusion of acetone into the aqueous phase, thus inducing the formation of nanospheres. The selection of the saltingout agent is important, because it can play an important role in the encapsulation efficiency of the drug. Both the solvent and the salting-out agent are then eliminated by cross-flow filtration [72].

This technique used in the preparation of PLA, poly(methacrylic) acid, and EC nanospheres leads to high efficiency and is easily scaled up [72]. The main advantage of salting out is that it minimizes stress to protein encapsulants [7]. Salting out does not require an increase of temperature and, therefore, may be useful when heatsensitive substances have to be processed [87]. The greatest disadvantages are exclusive application to lipophilic drugs and the extensive nanoparticle washing steps [1]. The preparative steps of this procedure are described in Figure 4.

\section{Production of nanoparticles from natural macromolecules}

\section{Albumin nanoparticles produced in an external-oily emulsion}

Two main methods are used in the preparation of albumin microspheres, characterized by the method of stabilization; thermal treatment at elevated temperatures $\left(95^{\circ}-170^{\circ} \mathrm{C}\right)$ or chemical treatment in vegetable oil, iso-octane emulsions, or aqueous medium. Other techniques involve slight modification of either of the two methods [88]. In this case albumin nanospheres were formed by homogenizing the oil phase containing the albumin droplets and thermally stabilized by heating at $175^{\circ}$ to $180^{\circ} \mathrm{C}$ for 10 minutes [88]. This mixture was cooled and diluted with ethyl ether to reduce the viscosity of the oil phase to permit separation by centrifugation.

Heat treatment of albumin is applicable only to drug molecules that are not heat sensitive. For this reason, nanoparticles were produced emulsifying serum albumin aqueous solution in cottonseed oil at $25^{\circ} \mathrm{C}$ [89], then denaturing the albumin by resuspending the particles in ether containing the cross-linking agents 2,3-butadiene or formaldehyde. The particles were stirred, isolated by centrifugation, and dried by lyophilization. Particles released the drug doxorubicin much faster than particles formed by heat treatment [89], but the purification step remains the main problem with the elimination of the cottonseed oil [3]. A technique was proposed based on the desolvation of natural macromolecules, which simplifies the purification step [90].

As a modification of this method [91], an aqueous solution of albumin was emulsified in chloroform containing hydroxypropylcellulose and EC as stabilizers. The emulsified macromolecule is subsequently cross-linked with glutaraldehyde and washed. Because of the need for chlorinated solvents, this technique does not offer much advantage over the other techniques [90].

Gelatin nanoparticles produced in an external-oily emulsion

Emulsified gelatin solution droplets were hardened by cooling the emulsion below the gelation point in an ice bath, 


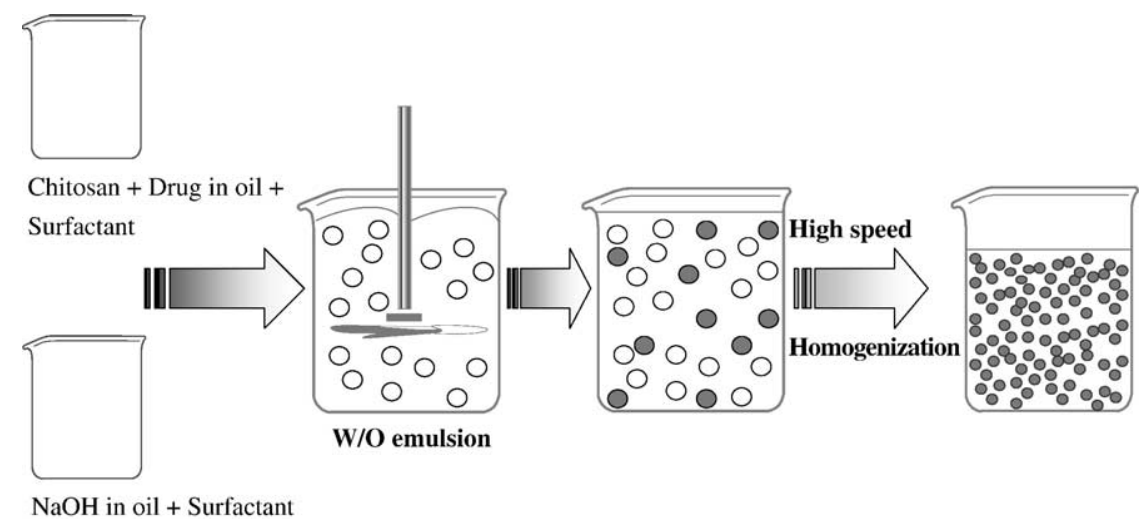

Fig 6. Schematic representation of chitosan nanoparticles preparation by the emulsification technique.

resulting in gelation of the gelatin droplets. Gelled nanodroplets were filtered, washed, and cross-linked with formaldehyde [92]. The particle size ranged between 100 and $600 \mathrm{~nm}$ with a mean of $280 \mathrm{~nm}$ [23]. This technique is applicable to heat-sensitive drugs; however, a number of drugs can be covalently bound to the gelatin by formaldehyde treatment, which constitutes a disadvantage [23]. Additionally, cross-linking increases significantly the size of the particles. Furthermore, a significant disadvantage of the cross-linking agent relates to its toxicity, and this point must be carefully considered. In this context, it would be of interest to study carefully the influence of different formulation and process parameters in this process according to the application.

Another interesting system for drug delivery systems could be nanoparticulate carriers from bioacceptable macromolecules. For this reason, vegetable protein fractions termed gliadins have been chosen from wheat gluten, to efficiently encapsulate lipophilic substances such as $\alpha$-tocopherol [93]. Gliadins possess the ability to interact with epidermal keratin as a result of their richness in praline; this property leads to a desired controlled release of drug.

\section{Alginate nanoparticles}

Sodium alginate is a water-soluble polymer that gels in the presence of multivalent cations such as calcium [94]. Alginate particles are usually produced by dropwise extrusion of sodium alginate solution into calcium chloride solution. Alginate particle size depends on the size of the initial extruded droplet. The smallest particles produced had a minimum size of 1 to $5 \mu \mathrm{m}$, obtained by air atomization [95]. The preparation of alginate nanoparticles was first achieved in a diluted aqueous sodium alginate solution in which gelation was induced by the addition of a low concentration of calcium. This leads to the formation of invisible clusters of calcium alginate gels. In an additional advance, alginate particles have been produced by using a modified emulsification/internal gelation method [96] as illustrated in Figure 5. The preparation of alginate nanoparticles via this method does not require specialized equipment and can be performed at ambient temperature. The main difficulty of this method is the nanoparticle washing step to eliminate the residual oil droplets, but new strategies have been devised.

\section{Chitosan nanoparticles}

Chitosan nanoparticles have been developed to encapsulated proteins such as bovine serum albumin, tetanus and diphtheria toxoid [6], vaccines [97], anticancer agents [98], insulin [99], and nucleic acids [100,101]. Chitosan considerably enhanced the absorption of peptides such as insulin and calcitonin across the nasal epithelium [102].

The methods proposed to prepare chitosan nanoparticles are based on the spontaneous formation of complexes between chitosan and polyanions [103] or the gelation of a chitosan solution dispersed in an oil emulsion [104]. Various methods for producing chitosan nanoparticles are described in the literature $[105,106]$.

Chitosan nanoparticles obtained by formation of a spontaneous complex between chitosan and polyanions such as tripolyphosphate [103] have small diameters $(200-500 \mathrm{~nm})$ and show a quasi spherical shape under transmission electron microscopy. Chitosan nanoparticles produced by a promoting gelation in an emulsification-based method as illustrated in Figure 6, results in a diameter of $400 \mathrm{~nm}$. Compared with the previously described method, this technique has a major disadvantage of involving organic solvents during the isolation of the particles; these are difficult to remove and may cause toxicity [107].

\section{Agarose nanoparticles}

Agarose nanoparticles were developed for the administration of therapeutic proteins and peptides [108]. Agarose aqueous solution forms thermally reversible hydrogels while being cooled below the gelling temperature $\left(31^{\circ}-36^{\circ} \mathrm{C}\right)$. Thermal gelation results from the formation of helicoidal structures responsible for a three-dimensional network in which large amounts of water can be entrapped. The hydrogel, being hydrophilic, inert, and biocompatible, forms a suitable matrix for proteins and peptides that can be entrapped in the gel during formation [107].

Agarose nanoparticles were produced using an emulsion-based technology as illustrated in Figure 7. This methodology requires the preparation of an agarose 


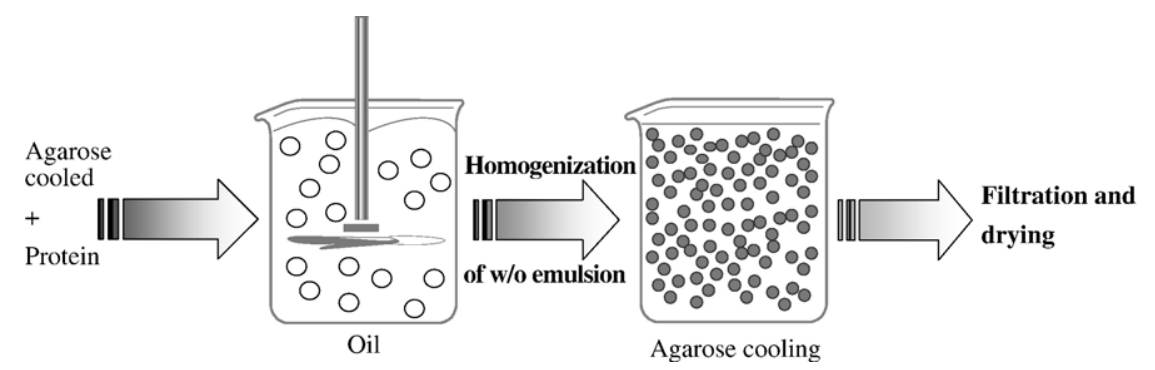

Fig 7. Schematic illustration of agarose nanoparticles preparation by the emulsification technique.

solution in corn oil emulsion at $40^{\circ} \mathrm{C}$ [109]. Peptides and proteins to be encapsulated are initially added to the agarose solution. The small size of the dispersed aqueous nanodroplets is achieved by homogenization. Gelation of agarose is then induced by diluting the emulsion with cold corn oil under agitation at $5^{\circ} \mathrm{C}$. The liquid nanodroplets then gel to protein-containing agarose hydrogel nanoparticles.

\section{Nanoparticles produced by desolvation of macromolecules}

Another technology applicable to a wide range of polymers is based on desolvation by charge and $\mathrm{pH}$ changes, or by addition of a desolvating agent (ethanol or concentrated inorganic salt solutions). The main advantage is that this process does not require an increase in temperature and, therefore, may be useful when heatsensitive drugs are used [110].

Nanoparticles were prepared using the process of reversible swelling of macromolecules $[90,111]$ using gelatin [111], human serum albumin [111], bovine serum albumin [112], and casein [111] as the macromolecular materials. This process offers the advantage of producing nanoparticles directly in aqueous suspension, but the use of potentially toxic compounds such as glutaraldehyde and desolvating agents requires subsequent purification [1]. Variations in nanoparticle production by the desolvation process were described [113], but unfortunately the yield is comparatively low. In the case of gelatin, different methods such as the two-step desolvation method [114,115] have been applied to produce nanoparticles. Recent reports outline the important use of gelatin as drug delivery systems for DNA [116] and cytostatics [117].

\section{New techniques based on supercritical or compressed fluids}

Some of the techniques described above are complex, and the products may often be characterized by high residual solvent content, low drug loading, drug degradation or denaturation, ineffective drug release, or unsuitable physical and morphological properties [118]. Techniques based on supercritical or compressed fluid can be an interesting tool for preparation of nanoparticulate and microparticulate products [119]. In this technique, the drug and the polymer are solubilized in a supercritical fluid, and the solution is expanded through a nozzle. The supercritical fluid is evaporated in the spraying process, and the solute particles eventually precipitate. This technique is clean, because the precipitated solute is free of solvent. It also provides advantages such as suitable technological and biopharmaceutical properties and high quality. It has been demonstrated for numerous applications involving protein drug delivery systems. Protein drugs such as insulin were encapsulated in poly(ethylene glycol)/poly(l-lactide) (PEG/ PLA) nanoparticles by this technique [130]. However, this new process requires a high initial capital investment for equipment, and elevated operating pressures requiring highpressure equipment. In addition, compressed supercritical fluids require elaborate recycling measures to reduce energy costs. Finally, it is very difficult to dissolve strong polar substances in supercritical $\mathrm{CO}_{2}$. In fact, supercritical $\mathrm{CO}_{2}$ has solvating properties characteristic of both fluorocarbons and hydrocarbons. However, the use of cosolvents and/or surfactants to form microemulsions makes it possible to dissolve polar and ionic species.

\section{Stability upon storage of the nanoparticles}

Nanoparticles are intended to be administered as pharmaceutical dosage forms in humans. Among other requirements, they must be free of impurities. The necessity for and degree of purification are dependent on the final purpose of the formulation developed. The most commonly reported procedures are gel filtration, ultracentrifugation, dialysis, and, recently, cross-flow filtration. Another requirement relates to the sterilization of the formulation. The choice of the sterilizing treatment depends on the physical susceptibility of the system. Finally, nanoparticles should be easily stored and administered. Nanoparticles constitute a relatively stable physical system because of their colloidal nature. Many variables can affect the stability of nanoparticles. Generally, a colloidal suspension is stable and does not tend to separate as a result of slow deposition due to the mixing tendencies of diffusion and convection. However, some agglomeration can occur. To prevent a complete precipitation, it is necessary to incorporate some additives. Chemical integrity of drug is also a fundamental aspect of the overall stability evaluation of the nanoparticles. Some parameters are crucial for the stability, such 
Table 2

Polymeric nanoparticles: general advantages and drawbacks of the preparation methods

\begin{tabular}{|c|c|c|c|c|c|}
\hline Method & $\begin{array}{l}\text { Simplicity } \\
\text { of procedure }\end{array}$ & $\begin{array}{l}\text { Need } \\
\text { for purification }\end{array}$ & $\begin{array}{l}\text { Facility } \\
\text { scaling-up }\end{array}$ & $\begin{array}{l}\mathrm{EE} \\
(\%)\end{array}$ & $\begin{array}{l}\text { Safety } \\
\text { of compounds }\end{array}$ \\
\hline \multicolumn{6}{|l|}{ Polymerization of monomers } \\
\hline \multicolumn{6}{|l|}{ Emulsion polymerization } \\
\hline Organic & Low & High & NR & Low & Low \\
\hline Aqueous & High & High & High & High & Medium \\
\hline Interfacial polymerization & Low & High & Medium & High & Low \\
\hline \multicolumn{6}{|l|}{ Preformed polymers } \\
\hline \multicolumn{6}{|l|}{ Synthetic } \\
\hline Emulsification/solvent evaporation & High & Low & Low & Medium & Medium \\
\hline $\begin{array}{l}\text { Solvent displacement and } \\
\text { interfacial deposition }\end{array}$ & High & NR & NR & High & Medium \\
\hline Salting out & High & High & High & High & Low \\
\hline Emulsion/solvent diffusion & Medium & Medium & High & High & Medium \\
\hline \multicolumn{6}{|l|}{ Natural } \\
\hline Albumin & NR & High & NR & Medium & Low \\
\hline Gelatin & NR & High & NR & Medium & Low \\
\hline \multicolumn{6}{|l|}{ Polysaccharides } \\
\hline Alginate & High & Medium & High & High & High \\
\hline Chitosan & High & Medium & High & High & High \\
\hline Agarose & Medium & High & NR & NR & High \\
\hline Desolvation & NR & High & NR & Low & Low \\
\hline
\end{tabular}

EE, encapsulation efficiency; NR, no reference available.

as the duration of contact with the aqueous environment when the drug is water soluble, the surrounding $\mathrm{pH}$ when drug degradation is $\mathrm{pH}$ dependent, and light exposure when the drug is light sensitive. Stability studies are thus important and can be performed according to the drug and to the polymer properties.

There are some methods to increase the stability of the nanoparticles. Lyophilization (freeze-drying) seems to be a highly stabilizing process. It is generally applied to enhance the physicochemical stability of the nanoparticles to achieve a pharmaceutically acceptable product, especially in cases in which the storage conditions are unfavorable. This technique involves the freezing of the suspension and subsequent elimination of its water content by sublimation under reduced pressure. After complete desiccation, nanoparticles are obtained in the form of a dry powder that is easy to handle and store. In most cases the freeze-dried particles are readily dispersible in aqueous solutions. In some systems the ease of redispersion depended on the manufacturing process. Ultrasonication was applied by some authors to ensure complete redispersion of nanoparticles.

Freezing is the most aggressive step of the freeze-drying operation for colloidal operations. It is thus important to improve the nanoparticle resistance by addition of a cryoprotectant to avoid alteration of the suspension [120]. Sometimes cryoprotectants like glucose, trealose, mannitol, and sorbitol were added to ensure redispersibilty or to allow vitrification of the suspension during the cooling and to avoid crystallization of the liquid suspension. It is also important to be aware of the presence of pharmaceutical excipients, usually used for purposes of isotonicity (eg, glucose) or stabilization (eg, dextran and surfactants). Such excipients are indeed cryoprotectants that facilitate the aqueous reconstitution of the freeze-dried product.
Finally, nanoparticles can be stored in sealed vials at room temperature, or in a laboratory desiccator, or even in the refrigerator, especially for temperature-sensitive drugs.

\section{Summary and conclusions}

The most important methods for the preparation of nanoparticulate drug carriers, together with their advantages and disadvantages, are summarized in Table 2.

The evolution of nanoparticle preparation methods has been marked by three aspects: need for less toxic reagents, simplification of the procedure to allow economic scale-up, and optimization to improve yield and entrapment efficiency. Efficient drug entrapment and transition to large scale are of utmost importance to industrial applicability.

There are now numerous preparation methods available for producing nanoparticles, and important technological advances have been achieved. Simple, safe, and reproducible techniques are now available to prepare drug-loaded nanospheres and nanocapsules. Depending on the physicochemical characteristics of a drug, it is now possible to choose the best method of preparation and the best polymer to achieve an efficient entrapment of the drug. The chosen method should minimize loss of the drug or its pharmacological activity. In this respect, the development of a technique that allows the incorporation of biomolecules without affecting their activity constitutes a fundamental goal for nanotechnology.

Nevertheless, there are several problems that remain to be solved. The process is not suitable to all drugs. In addition, the postpreparative steps, such as purification and preservation, particularly important for nanocapsules, and residual solvent analysis must be extensively investigated. Other difficulties remain, such as the formation of an incomplete or discontinuous film, inadequate stability of certain active components, nonreproducible or predictable release charac- 
teristics, and certain limitations that make the final product economically unfeasible.

Despite these technological challenges, nanoparticles have shown great promise for the development of drug administration.

\section{References}

[1] Couvreur P, Dubernet C, Puisieux F. Controlled drug delivery with nanoparticles: current possibilities and future trends. Eur J Pharm Biopharm 1995;41:2-13.

[2] Couvreur P. Polyalkylcyanoacrylates as colloidal drug carriers. Crit Rev Ther Drug Carrier Syst 1988;5:1-20.

[3] Allémann E, Gurny R, Doekler E. Drug-loaded nanoparticlespreparation methods and drug targeting issues. Eur J Pharm Biopharm 1993;39:173-91.

[4] McClean S, Prosser E, Meehan E, O’Malley D, Clarke N, Ramtoola $\mathrm{Z}$, et al. Binding and uptake of biodegradable poly-lactide microand nanoparticles in intestinal epithelia. Eur J Pharm Sci 1998;6: $153-63$.

[5] Benoit JP, Couvreur P, Devissaguet J-P, Fessi H, Puisieux F, RoblotTreupel L. Les formes vectorisées ou distribution modulée, nouveuax sistèmes d'administration medicaments. J Pharm Belg 1986;41:319-29.

[6] Soppimath KS, Aminabhavi TM, Kulkarni AR, Rudzinski WE. Biodegradable polymeric nanoparticles as drug delivery devices. J Control Release 2001;70:1-20.

[7] Jung T, Kamm W, Breitenbach A, Kaiserling E, Xiao JX, Kissel T. Biodegradable nanoparticles for oral delivery of peptides: is there a role for polymers to affect mucosal uptake? Eur J Pharm Biopharm 2000;50:147-60.

[8] Kumar N, Ravikumar MNV, Domb AJ. Biodegradable block copolymers. Adv Drug Deliv Rev 2001;53:23-44.

[9] Kreuter J. Large-scale production problems and manufacturing of nanoparticles. In: Tyle P, editor. Specialized drug delivery system. New York: Marcel Dekker; 1990. p. 257-66.

[10] Ekman B, Sjöholm I. Improved stability of proteins immobilized in microparticles prepared by modified emulsion polymerization technique. J Pharm Sci 1978;67:693-6.

[11] Lowe PJ, Temple CS. Calcitonin and insulin in isobutylcyanoacrylate nanocapsules: protection against proteases and effect on intestinal absorption in rats. J Pharm Pharmacol 1994;46:547-52.

[12] Kreuter J. Nanoparticle-based drug delivery systems. J Control Release 1991;16:169-76.

[13] El-Samaligy MS, Rohdewald P, Mahmoud HA. Polyalkylcyanoacrylate nanocapsules. J Pharm Pharmacol 1986;38:216-8.

[14] Krause HJ, Schwarz A, Rohdewald P. Interfacial polymerization, an useful method for the preparation of polymethylcyanoacrylate nanoparticles. Drug Dev Ind Pharm 1986;12:527-52.

[15] Harmia-Pulkkinen T, Tuomi A, Kristoffersson E. Manufacture of polyalkylcyanoacrylate nanoparticles with pilocarpine and timolol by micelle polymerization: factors influencing particle formation. J Microencapsul 1989;6:87-93.

[16] Vauthier C, Dubernet C, Fattal E, Pinto-Alphandary H, Couvreur P. Poly(alkylcyanoacrylates) as biodegradable materials for biomedical applications. Adv Drug Deliv Rev 2003;55:519-48.

[17] Kreuter J. The mechanism of termination in heterogeneous polymerization. J Polym Sci 1982;20:543-5.

[18] Kreuter J, Speiser P. New adjuvants on a polymethyl(methacrylate) base. Infect Immun 1976;13:204-10.

[19] Kreuter J. Evaluation of nanoparticles as drug-delivery system. I. Preparation methods. Pharm Acta Helv 1983;58:196-209.

[20] Rolland A, Gibassier D, Sado P, Le Verge R. Purification et propriétés physico-chimiques des suspensions de nanoparticules de polymère. J Pharm Belg 1986;41:94-105.
[21] Kreuter J, Täuber U, Illi V. Distribution and elimination of poly(methyl-2- ${ }^{14} \mathrm{C}$-methacrylate) nanoparticle radioactivity after injection in rats and mice. J Pharm Sci 1979;68:1443-7.

[22] Grislain L, Couvreur P, Lenaerts V, Roland M, Deprez-Decampeneere D, Speiser PP. Pharmacokinetics and distribution of a biodegradable drugcarrier. Int J Pharm 1983;15:335 - 45.

[23] Kreuter J. Nanoparticles - preparation and applications. In: Donbrow $\mathrm{M}$, editor. Microcapsules and nanoparticles in medicine and pharmacy. London: CRC Press Boca Raton; 1992. p. 125-48.

[24] Seijo B, Fattal E, Roblot-Treupel L, Couvreur P. Design of nanoparticles of less than $50 \mathrm{~nm}$ diameter: preparation, characterization and drug loading. Int J Pharm 1990;62:1-7.

[25] Némati F, Dubernet C, Fessi H, Verdière AC, Poupon MF, Puisieux $\mathrm{F}$, et al. Reversion of multidrug resistance using nanoparticles in vitro: influence of the nature of the polymer. Int J Pharm 1996;138: 237- 46.

[26] Bapat N, Boroujerdi M. Uptake capacity and adsorption isotherms of doxorubicin on polymeric nanoparticles: effect of methods of preparation. Drug Dev Ind Pharm 1992;18:65-77.

[27] Li VHK, Wood RW, Kreuter J, Harmia T, Robinson JR. Ocular drug delivery of progesterone using nanoparticles. J Microencapsul 1986; 3:213-8,

[28] El-Samaligy MS, Rohdewald P. Triamcinolone diacetate nanoparticles a sustained release drug delivery system suitable for parental administration. Pharm Acta Helv 1982;57:201-4.

[29] Michel C, Roques M, Couvreur P, Vranchx H, Baldschmidt P. Isobutylcyanoacrylate nanoparticles as drug carrier for oral administration of insulin. Proc Int Symp Control Release Bioact Mater 1991;18:97-8.

[30] Grangier JL, Puygrenier M, Gauthier JC, Couvreur P. Nanoparticles as carriers for growth hormone releasing factors (GRF). J Control Release 1991;15:3 - 13.

[31] Kubiak C, Manil L, Couvreur P. Sorptive properties of antibodies onto cyanoacrylic nanoparticles. Int J Pharm 1988;41:181-7.

[32] Lescure F, Zimmer C, Roy D, Teulon JM, Couvreur P. Synthesis and evaluation of a new biodegradable monomer. Proc Int Symp Contr Rel Bioact Matter 1991;18:325-6.

[33] Mbela TKM, Poupaert JH, Dumont P. Poly(diethylmethyldene malonate) nanoparticles as primaquine delivery system to liver. Int J Pharm 1992;79:29-38.

[34] Couvreur P, Barrat G, Fattal E, Legrand P, Vauthier C. Nanocapsule technology. Crit Rev Ther Drug Carrier Syst 2002;19:99-134.

[35] Al Khouri N, Roblot-Treupel L, Fessi H, Devissaguet JP, Puisieux F. Development of a new process for the manufacture of polyisobutylcyanoacrylate nanocapsules. Int J Pharm 1986;28:125-32.

[36] Watnasirichaikul S, Davies NM, Rades T, Tucker IG. Preparation of biodegradable insulin nanocapsules from biocompatible microemulsions. Pharm Res 2000;17:684-9.

[37] Aprahamian M, Michel C, Humbert W, Devissaguet J-P, Damgé C. Transmucosal passage of polyalkylcyanoacrylate nanocapsules as a new drug carrier in the small intestine. Biol Cell 1987;61: $69-76$.

[38] Lambert G, Fattal E, Pinto-Alphandary H, Gulik A, Couvreur P. Polyisobutylcyanoacrylate nanocapsules containing an aqueous core as a novel colloidal carrier for the delivery of oligonucleotides. Pharm Res 2000;17:707-14.

[39] Lenaerts V, Labib A, Chouinard F, Rousseau J, Ali H, Lier J. Nanocapsules with a reduced liver uptake: targeting of phthalocyanines to EMT-6 mouse mammary tumour in vivo. Eur J Pharm Biopharm 1995;41:38-43.

[40] Damgé C, Michel C, Aprahamian M, Couvreur P. New approach for oral administration of insulin with polyalkylcyanoacrylate nanocapsules as drug carrier. Diabetes 1988;37:246-51.

[41] Damgé C, Vonderscher J, Marbach P, Pinget M. Poly(alkylcyanoacrylate) nanocapsules as a delivery system in the rat for octreotide, a long-acting somatostatin analogue. J Pharm Pharmacol 1997;49: $949-54$. 
[42] Hubert B, Atkinson J, Guerret M, Hoffman M, Devissaguet J-P, Maincent $\mathrm{P}$. The preparation and acute antihypertensive effects of a nanocapsular form of darodipine, a dihydropyridine calcium entry blocker. Pharm Res 1991;8:734-8.

[43] Gürsoy A, Eroglu L, Ulutin S, Tasyürek M, Fessi H, Puisieux F, et al. Evaluation of indomethacin nanocapsules for their physical stability and inhibitory activity on inflammation and platelet aggregation. Int J Pharm 1989;52:101 -8.

[44] Ammoury N, Fessi H, Devissaguet J-P, Dubrasquet M, Benita S. Jejunal absorption, pharmacological activity, and pharmacokinetic evaluation of indomethacin-loaded poly(D,L-lactide) and poly(isobutylcyanoacrylate) nanocapsules in rats. Pharm Res 1991;8:101-5.

[45] Vranchx H, Demoustier M, Deleers M. A new nanocapsule formulation with hydrophilic core: application to the oral administration of salmon calcitonin. Eur J Pharm Sci 1996;42:345 - 7 .

[46] Vranchx H, Demoustier M. Deleers M, Pharmaceutical compositions containing nanocapusles. US Patent 5.500.224. 1996.

[47] Allémann E, Leroux JC, Gurny R. Polymeric nano-microparticles for the oral delivery of peptides and peptidomimetics. Adv Drug Deliv Rev 1998;34:171-89.

[48] Montasser I, Fessi H, Coleman AW. Atomic force microscopy imaging of novel type of polymeric colloidal nanostructures. Eur J Pharm Biopharm 2002;54:281 - 4 .

[49] Bouchemal K, Briancon S, Perrier E, Fessi H, Bonnet I, Zydowicz N. Synthesis and characterization of polyurethane and poly(ether urethane) nanocapsules using a new technique of interfacial polycondensation combined to spontaneous emulsification. Int $\mathrm{J}$ Pharm 2004;269:89-100.

[50] Tice TR, Gilley RM. Preparation of injectable controlled-release microcapsules by solvent-evaporation process. J Control Release 1985;2:343 - 52 .

[51] Aftabrouchard D, Dorlker E. Preparation methods for biodegradable microparticles loaded with water-soluble drugs. STP Pharma Sci 1992;2:365-80.

[52] Gurny R, Peppas NA, Harrington DD, Banker GS. Development of biodegradable and injectable lattices for controlled release of potent drugs. Drug Dev Ind Pharm 1981;7:1-25.

[53] Ueda H, Kreuter J. Optimization of the preparation of loperamideloaded poly (1-lactide) nanoparticles by high pressure emulsification solvent evaporation. J Microencapsul 1997;14:593-605.

[54] Tabata J, Ikada Y. Protein pre-coating of polylactide microspheres containing a lipophilic immunopotentiator for enhancement of macrophage phagocytosis and activation. Pharm Res 1989;6:296-301.

[55] Bodmeier R, Chen H. Indomethacin polymeric nanosuspensions prepared by microfluidization. J Control Release 1990;12:223 -33.

[56] Gref R, Minamitake Y, Peracchia MT, Trubetskoy V, Torchilin V, Langer R. Biodegradable long circulating nanospheres. Science 1994;263:1600-3.

[57] Kumar MVR. Nano and microparticles as controlled drug delivery devices. J Pharm Sci 2000;3:234-58.

[58] Lemarchand C, Gref R, Passirani C, Garcion E, Petri B, Muller R. Influence of polysaccharide coating on the interactions of nanoparticles with biological systems. Biomaterials 2006;27:108-18.

[59] Koosha F, Muller RH, Washington C. Production of polyhydroxybutyrate (PHB) nanoparticles for drug targeting. J Pharm Pharmacol 1987;39:136P.

[60] Koosha F, Muller RH, Davis SS, Davies MC. The surface chemical structure of poly( $\beta$-hydroxybutyrate) microparticles produced by solvent evaporation process. J Control Release 1989;9:149-57.

[61] Landry FB, Bazile DV, Spenlehauer G, Veillard M, Kreuter J. Influence of coating agents on the degradation of poly(d,l-lactic acid) nanoparticles in model digestive fluids (USP XXII). STP Pharma Sci 1996;6:195-202.

[62] Tobío M, Gref R, Sánchez A, Langer R, Alonso MJ. Stealth PLAPEG nanoparticles as protein carriers for nasal administration. Pharm Res 1998; 15:270-5.
[63] Ueda M, Iwara A, Kreuter J. Influence of the preparation methods on the drug release behavior of loperamide-loaded nanoparticles. J Microencapsul 1998;15:361 - 72.

[64] Mainardes RM, Evangelista RC. PLGA nanoparticles containing praziquantel: effect of formulation variables on size distribution. Int $\mathrm{J}$ Pharm 2005;290:137-44.

[65] Jaiswal J, Gupta SK, Kreuter J. Preparation of biodegradable cyclosporine nanoparticles by high-pressure emulsification-solvent evaporation process. J Control Release 2004;96:169-78.

[66] Sánchez A, Vila Jato JL, Alonso MJ. Development of biodegradable microspheres and nanospheres for the controlled release of cyclosporine. Int J Pharm 1993;99:263 - 73.

[67] Prabha S, Zhou W-Z, Panyam J, Labhasetwar V. Size-dependency of nanoparticle-mediated gene transfection studies with fractionated nanoparticles. Int J Pharm 2002;244:105 - 15.

[68] Fessi H, Puisieux F, Devissaguet J-P, Ammoury N, Benita S. Nanocapsule formation by interfacial deposition following solvent displacement. Int J Pharm 1989;55:R1 - R4.

[69] Barichello JM, Morishita M, Takayama K, Nagai T. Encapsulation of hydrophilic and lipophilic drugs in PLGA nanoparticles by the nanoprecipitation method. Drug Dev Ind Pharm 1999;25:471-6.

[70] Galindo-Rodriguez S, Allémann E, Fessi H, Doelker E. Physicochemical parameters associated with nanoparticle formation in the salting-out, emulsification-diffusion, and nanoprecipitation methods. Pharm Res 2004;21:1428 - 39.

[71] Ganachaud F, Katz JL. Nanoparticles and nanocapsules created using the ouzo effect: Spontaneous emulsification as an alternative to ultrasonic and high-shear devices. Chem Phys Chem 2005;6: 209 - 16.

[72] Quintanar-Guerrero D, Allémann E, Fessi H, Doelker E. Preparation techniques and mechanism of formation of biodegradable nanoparticles from preformed polymers. Drug Dev Ind Pharm 1998;24: 1113-28.

[73] Dimitrova B, Ivanov IB, Nakache E. Mass transport effects on the stability of emulsion films with acetic acid and acetone diffusing across the interface. J Disp Sci Technol 1988;9:321 -41.

[74] Wehrle P, Magenheim B, Benita S. Influence of process parameters on the PLA nanoparticle size distribution, evaluated by means of factorial design. Eur J Pharm Biopharm 1995;41:19-26.

[75] Molpeceres J, Guzman M, Aberturas MR, Chacon M, Berges L. Application of central composite designs to the preparation of polycaprolactone nanoparticles by solvent displacement. J Pharm Sci 1996;85:206-13.

[76] Irache JM, Huici M, Konecny M, Espuelas S, Campanero MA, Arbos P. Bioadhesive properties of gantrez nanoparticles. Molecules 2005; $10: 126-45$.

[77] Arbós P, Wirth M, Arangoa MA, Gabor F, Irache JM. Gantrez ${ }^{\circledR}$ AN as a new polymer for the preparation of ligand-nanoparticle conjugates. J Control Release 2002;83:321 -30.

[78] Memisoglu E, Bochot A, Özalp M, Sen M, Duchêne D, Hincal A. Direct formation of nanospheres from amphiphilic beta-cyclodextrin inclusion complexes. Pharm Res 2003;20:117-25.

[79] Ammoury N, Fessi H, Devissaguet J-P, Puisieux F, Benita S. In vitro release pattern of indomethacin from poly(D,L-lactide) nanocapsules. J Pharm Sci 1990;79:763-7.

[80] Vargas A, Pegaz B, Debefve E, Konan-Kouakou Y, Lange N, Ballini $\mathrm{J}-\mathrm{P}$, et al. Improved photodynamic activity of porphyrin loaded into nanoparticles: an in vivo evaluation using chick embryos. Int J Pharm 2004;286:131-45.

[81] Konan YN, Gurny R, Allémann E. State of the art in the delivery of photosensibilizers for photodynamic therapy. Photochem Photobiol B 2002;66:89-106.

[82] Yoo HS, Oh JE, Lee KH, Park TG. Biodegradable nanoparticles containing PLGA conjugate for sustained release. Pharm Res 1999;16:1114-8.

[83] Perez C, Sánchez A, Putnam D, Ting D, Langer R, Alonso MJ. Poly(lactic acid)-poly(ethylene glycol) nanoparticles as new car- 
riers for the delivery of plasmid DNA. J Control Release 2001; 75:211-24.

[84] Lu W, Zhang Y, Tan Y-Z, Hu K-L, Jiang X-G, Fu S-K. Cationic albumin-conjugated pegylated nanoparticles as novel drug carrier for brain delivery. J Control Release 2005;107:428-48.

[85] Saxena V, Sadoqi M, Shao J. Indocyanine green-loaded biodegradable nanoparticles: preparation, physicochemical characterization and in vitro release. Int J Pharm 2004;278:293-301.

[86] El-Shabouri MH. Positively charged nanoparticles for improving the oral bioavailability of cyclosporin-A. Int J Pharm 2002;249: $101-8$.

[87] Lambert G, Fattal E, Couvreur P. Nanoparticulate system for the delivery of antisense oligonucleotides. Adv Drug Deliv Rev 2001;47:99-112.

[88] Patil GV. Biopolymer albumin for diagnosis and in drug delivery. Drug Dev Res 2003;58:219-47.

[89] Widder KJ, Flouret G, Senye A. Magnetic microspheres: synthesis of a novel parenteral drug carrier. J Pharm Sci 1979;68:79-82.

[90] Marty JJ, Oppenheim RC, Speiser P. Nanoparticles - a new colloidal drug system delivery system. Pharm Acta Helv 1978;53:17-23.

[91] Longo WE, Iwata H, Lindheimer TA, Goldberg EP. Preparation of hydrophilic albumin microspheres using polymeric dispersing agents. J Pharm Sci 1982;71:1323-8.

[92] Yoshioka T, Hashida M, Muranishi S, Sezaki H. Specific delivery of mitomycin $\mathrm{C}$ to the liver, spleen, and lung: nano- and microspherical carriers of gelatin. Int J Pharm 1981;8:131-41.

[93] Duclairoir C, Orecchioni AM, Depraetere P, Nakache E. $\alpha$-Tocopherol encapsulation and in vitro release from wheat gliadin nanoparticles. J Microencapsul 2002;19:53-60.

[94] Aslani P, Kennedy RA. Studies on diffusion in alginate gels. I. Effect of cross-linking with calcium or zinc ions on diffusion of acetaminophen. J Control Release 1996;42:75-82.

[95] Kwok KK, Groves MJ, Burgess DJ. Production of 5-15 $\mu \mathrm{m}$ diameter alginate-polylysine microcapsules by an air atomization technique. Pharm Res 1991;8:341 - 4.

[96] Reis CP, Neufeld RJ, Ribeiro AJ, Viega F. Insulin-alginate nanospheres: influence of calcium on polymer matrix properties. Proceedings of the 13th International Workshop on Bioencapsulation. Kingston, Ontario, Canada: Queen's University; 2005.

[97] Vila A, Sánchez A, Janes KA, Behrens I, Kissel T, Vila-Jato JL, et al. Low molecular weight chitosan nanoparticles as new carriers for nasal vaccine delivery in mice. Eur J Pharm Biopharm 2004; 57:123-31.

[98] Janes KA, Fresneau MP, Marazuela A, Fabra A, Alonso MJ. Chitosan nanoparticles as delivery systems for doxorubicin. J Control Release 2001;73:255 -67.

[99] Ma Z, Lim TM, Lim L-Y. Pharmacological activity of peroral chitosan-insulin nanoparticles in diabetic rats. Int $\mathrm{J}$ Pharm 2005;293:271-80.

[100] Mansouri S, Lavigne P, Corsi K, Benderdour M, Beaumont E, Fernandes JC. Chitosan-DNA nanoparticles as non-viral vectors in gene therapy: strategies to improve transfection efficacy. Eur J Pharm Biopharm 2004;57:1 -8.

[101] Mao H-Q, Roy K, Troung-Le VL, Janes KA, Lin KY, Wang Y, et al. Chitosan-DNA nanoparticles as gene carriers: synthesis, characterization and transfection efficiency. J Control Release 2001;70:399-421.

[102] Illum L, Farraj NF, Davis SS. Chitosan as novel nasal delivery system for peptide drugs. Pharm Res 1994;11:1186-9.

[103] Calvo P, Remuñan-Lopez C, Vila-Jato JL, Alonso MJ. Chitosan and chitosan/ethylene oxide-propylene oxide block copolymer nanoparticles as novel carriers for proteins and vaccines. Pharm Res 1997; $14: 1431-6$.

[104] Tokumitsu H, Ichikawa H, Fukumori Y, Hiratsuka J, Sakurai Y, Kobayashi T. Preparation of gadopentetate-loaded chitosan nanoparticles for gadolinium neutron capture therapy of cancer using a novel emulsion droplet coalescence technique. Proceedings of the 2nd World Meeting on Pharmaceutics, Biopharmaceutics and Pharmaceutical Technology, APGI/APV; Paris; 1998. p. 641-2.

[105] Aktas Y, Andrieux K, Alonso MJ, Calvo P, Gürsoy RN, Couvreur P. Preparation and in vitro evaluation of chitosan nanoparticles containing a caspase inhibitor. Int J Pharm 2005;298:378-83.

[106] Agnihotri SA, Mallikarjuna NN, Aminabhavi TM. Recent advances on chitosan-based micro- and nanoparticles in drug delivery. J Control Release 2004;100:5-28.

[107] Vauthier C, Couvreur P. Development of polysaccharide nanoparticles as novel drug carrier systems. In: Wise DL, editor. Handbook of pharmaceutical controlled release technology. New York: Marcel Dekker; 2000. p. 413-29.

[108] Wang N, Wu XS, Mesiha M. A new method for preparation of protein-loaded agarose nanoparticles. Pharm Res 1995;12:S257.

[109] Wang N, Wu XS. Preparation and characterization of agarose hydrogel nanoparticles for protein and peptide drug delivery. Pharm Dev Technol 1997;2:135-42.

[110] Ibrahim H, Bindschaedler C, Doelker E, Buri P, Gurny R. Aqueous nanodispersions prepared by a salting-out process. Int $\mathrm{J}$ Pharm 1992;87:239-46.

[111] Marty JJ. The preparation, purification and properties of nanoparticles. D. Pharm Thesis Parkville (Australia): Victorian College of Pharmacy; 1977, p. 30.

[112] Weber C, Coester C, Kreuter J, Langer R. Desolvation process and surface characterization of protein nanoparticles. Int $\mathrm{J}$ Pharm 2000;194:91 - 102.

[113] El-Samaligy MS, Rohdewald P. Reconstituted collagen nanoparticles, a novel drug carrier delivery system. J Pharm Pharmacol 1983;35:537-9.

[114] Coester C, Langer K, Briesen HV, Kreuter J. Gelatin nanoparticles by two step desolvation - a new preparation method, surface modifications and cell uptake. J Microencapsul 2000;17:187-93.

[115] Zillies J, Coester C. Evaluating gelatin based nanoparticles as a carrier system for double stranded oligonucleotides. J Pharm Pharm Sci 2004;7:17-21.

[116] Zwiorek K, Kloeckner J, Qagner E, Coester C. Gelatin nanoparticles as a new and simple gene delivery system. J Pharm Pharm Sci 2004; 7:22-8.

[117] Lu Z, Yeh T-K, Tsai M, Au JL-S, Wientjes MG. Paclitaxel-loaded gelatin nanoparticles for intravesical bladder cancer therapy. Clin Cancer Res 2004;10:7677-84.

[118] Caliceti P, Salmaso S, Elvassore N, Bertucco A. Effective protein release from PEG/PLA nanoparticles produced by compressed gas anti-solvent precipitation techniques. J Control Release 2004;94:195-205.

[119] Wang Y, Dave RN, Pfeffer R. Polymer coating/encapsulation of nanoparticles using a supercritical anti-solvent process. J Supercrit Fluids 2004;28:85-99.

[120] Esquisabel A, Hernández RM, Igartua M, Gascón AR, Calvo B, Pedraz JL. Production of BCG alginate-PLL microcapsules by emulsification/internal gelation. J Microencapsul 1997;14:627-38.

[121] Kreuter J, Mauler R, Gruschkau H, Speiser PP. The use of new polymethylmethacrylate adjuvants for split influenza vaccines. Exp Cell Biol 1976;44:12-9.

[122] Couvreur P, Kante B, Lenaerts V, Scailteur V, Roland M, Speiser P. Tissue distribution of antitumour drugs associated with polyalkylcyanoacrylate nanoparticles. J Pharm Sci 1980;69:199-202.

[123] Radwan MA, Aboul-Enein HY. The effect of the oral absorption enhancers on the in vivo performance of insulin-loaded poly(ethylcyanoacrylate) nanospheres in diabetic rats. J Microencapsul 2002; 19:225-35.

[124] Maincent P, Le Verge R, Sado P, Couvreur P, Devissaguet J-P. Disposition kinetics and oral bioavailability of vincamine-loaded polyalkyl cyanoacrylate nanoparticles. J Pharm Sci 1986;75: $955-8$.

[125] Arbós P, Campanero MA, Arangoa MA, Renedo MJ, Irache JM. Influence of the surface characteristics of PVM/MA nanoparticles on their bioadhesive properties. J Control Release 2003;89:19-30. 
[126] Allémann E, Leroux JC, Gurny R, Doekler E. In vitro extendedrelease properties of drug-loaded poly(d,1-lactic acid) nanoparticles produced by salting-out procedure. Pharm Res 1993;10: $1732-7$.

[127] Konan YN, Berton M, Gurny R, Allémann E. Enhanced photodynamic activity of meso-tetra(4-hydroxyphenyl)porphyrin by incorporation into sub-200 nm nanoparticles. Eur J Pharm Sci 2003; 18:241-9.

[128] Aynié I, Vauthier C, Fattal E, Puisieux F, Couvreur P. Role of a small polylysine in a hydrogel nanoparticulate system for the antisense oligonucleotide strategy. Proceedings of the 2nd World Meeting on Pharmaceutics, Biopharmaceutics and Pharmaceutical Technology, APGI/APV; Paris; 1998. p. 583-4.

[129] Aynié I, Vauthier C, Fattal E, Foulquier M, Couvreur P. Alginate nanoparticles as a novel carrier for antisense oligonucleotides. In: Muller H, editor. Future strategies for drug delivery with particulate systems. Boca Raton (FL): CRC Press; 1998. p. 11-6.

[130] Elvassore N, Bertucco A, Caliceti P. Production of insulin-loaded poly(ethylene glycol)/poly(l-Lactide) (PEG/PLA) nanoparticles by gas antisolvent techniques. J Pharm Sci 2001;90:1628-36. 